\title{
Correspondence
}

Correspondents should note that space is limited and shorter letters have a greater chance of publication. The Editors reserve the right to cut letters and also to eliminate multitudinous references. Please try to be concise, strictly relevant and interesting to the reader, and check the accuracy of all references in Journal style.

\section{CONCOMITANT ADMINISTRATION OF MIANSERIN AND WARFARIN}

DEAR SIR,

We wish to report a case in which there was an apparent interaction between the drugs mianserin and warfarin.

A sixty-three-year-old man was admitted to High Royds Hospital suffering from manic-depressive psychosis-depressed type (ICD 9, 296.1). Clinically he was severely depressed and presented a risk of suicide; antidepressant medication was therefore indicated. Two years previously he had suffered a cerebral embolism and consequent left hemiparesis; this was attributed to atrial fibrillation caused by previously undiagnosed thyrotoxicosis. He had made an almost full recovery and had been maintained since that time on anti-coagulant therapy with warfarin. Euthyroid status has been maintained with oral carbimazole.

An ECG was performed prior to antidepressant therapy and ischaemic changes recorded. This finding suggested that mianserin hydrochloride, a tetracyclic antidepressant claimed to possess few cardiotoxic sideeffects, would be the most appropriate treatment. We were aware of interactions between some tricyclic drugs and anticoagulants but the hospital pharmacist, British National Formulary and Data Sheet Compendium were consulted and no evidence was found to suggest that warfarin and mianserin might interact in the same way (Committee on Safety of Medicines, 1982).

The prothrombin time had been satisfactory during the six months prior to admission, on a dosage of $8 \mathrm{mg}$ warfarin daily. A prothrombin time estimation was performed prior to the commencement of mianserin; the result was 20 seconds, and British Standard Ratio 1.8. After a week's administration of mianserin $10 \mathrm{mg}$ daily, the prothrombin time was 25 seconds, British Standard Ratio 4.6; that is above the therapeutic range. Mianserin was therefore stopped and at the time of writing the prothrombin time had returned to within the therapeutic range. Thyroid and liver function were both checked prior to administration of mianserin and repeated after the drug was stopped, both were normal and remained unchanged. No other drugs were administered, apart from the daily dose of carbimazole which had been taken for almost two years, and there was no excessive alcohol consumption.

As a result of this experience we conclude that mianserin and warfarin may interact and cause an increase in the prothrombin time, with a risk of pathological bleeding. This may occur because mianserin is plasma protein bound and could therefore displace warfarin from the binding sites on these proteins. The concentration of unbound and therefore biologically active warfarin in the circulation would increase. Both of these drugs are in common use and indications for their concomitant administration cannot be uncommon. The interaction described could have serious and potentially lethal effects. For these reasons we believe that the combination should be avoided and appropriate warnings given to users of the drugs.

High Royds Hospital,

H. M. C. WARWICK

R. H. S. MindhaM

Menston, Ilkley,

W. Yorks LS296AQ

\section{DEPRESSION UNDERTREATED? YES, BUT . . .}

DEAR SIR,

I should like to endorse Dr Bridges' opinion in "Points of View" (Journal, June 1983, 142, 621) that 'undertreatment' of depression with antidepressant medication is a serious problem. The problem is perhaps even worse in elderly patients where it is genuinely rare for them to receive adequate doses of tricyclic drugs either from their GP's or from hospital psychiatrists. "A little bit of antidepressant for a little bit of depression" is guaranteed to bring all the problems of unpleasant side effects and no benefits. It is common for a patient to be referred after weeks of Imipramine $10 \mathrm{mg}$ daily or Prothiaden $25 \mathrm{mg}$ twice daily. Doctors are now thoroughly versed in all the unpleasant side effects and risks of using tricyclics in 